Since the introduction of the College 'accreditation' (now 'approval') exercise, each district service provides a considerable amount of postgraduate training. Case conferences and journal clubs are now standard. Study leave is encouraged and the number of academic meetings organised by the Divisions and the various parts of the College have proliferated. Clinical skills are now more often taught in the trainee's base hospital in what is now a more open and questioning climate. Given all this, do trainees still require a day release course?

It is still probably true that basic sciences are more available at the Regional Centre. Neuroanatomy, pathology, neurophysiology, neuropharmocology, ethology, to name but a few subjects which are relevant, are usually not available outside the teaching centre. The basic sciences used to be concentrated in the first year course. Now the new examination requires more to do with the clinical interview and basic phenomenology, and basic sciences are required in the Part II. Should we still concentrate the basic sciences in the first year on the assumption that they still form the basis of psychiatry or spread them throughout the course?

The Southampton course used to assume that basic clinical skills were taught at the base hospital. However, the new Part I has brought an increased demand for these to be taught on the first year course. How can skills training be incorporated without more didactic parts of the course being dropped?

Over the last two years we have radically altered the MRCPsych course and are now incorporating a research element as a course within the Part II course. We get feedback from our trainees and we can find out examination results (sometimes with difficulty). Is this information good enough or should our courses be judged by some other criterion? Certainly approval teams seem only to check whether a course exists or not prior to giving their approval or not. The approval teams do not have the time or the remit to look critically at individual courses.

My feeling is that the College should now take a closer interest in MRCPsych courses. Their funding will inevitably be questioned in the near future. Are they still needed as is implied on Approval team visits when approval may depend on their existence? Perhaps the Dean should encourage more interest in this rather neglected aspect of training. Some central collection of information on existing courses might form the basis for a meeting of course organisers to share ideas about the future of these courses.

University Department of Psychiatry

Peter NotT

Royal South Hants Hospital

Southampton SO9 4PE
DEAR SIRS

Dr Nott's letter is timely and well taken. The College should be looking at MRCPsych courses once again although it is certainly not the intention to jeopardise their jealously preserved independence. The Chief Examiner recently carried out a survey of MRCPsych courses and the results of this will be made known at the next meeting of the Education Committee.

There is still a need for day-release courses in psychiatry as the undergraduate medical curriculum still gives very much less background for postgraduate trainees in psychiatry than, for example, in general medicine. Medical undergraduate teaching in psychology and sociology is still very much less intensive than anatomy, physiology or pathology; the clerkship in psychiatry is much shorter than either that for medicine or surgery. This means that trainees coming into psychiatry have less theoretical background in their specialty than their colleagues and contemporaries in other medical specialties; it is important that they obtain this background, both for building their subsequent psychiatric knowledge and for communicating with other professionals in the mental health services.

Ideally, teaching of the basic sciences should now be spread throughout the MRCPsych course. It may be difficult to achieve this but it is more in line with the current aim of making basic sciences more relevant to clinical experience.

It is still the intention that basic clinical skills should be taught at the base hospital. Approval visits to training schemes enquire about the training in clinical skills. More theoretical aspects of training in psychiatry are of greater relevance to MRCPsych courses.

I would agree that there is a need for a meeting of course organisers. One of the matters for discussion would be the criteria for success of an MRCPsych course. I am grateful to Dr Nott for raising this important issue.

Professor ANDRew Sims Dean

\section{Auditing of audit}

\section{DEAR SIRS}

The Royal College of Psychiatrists Working Party on Medical Audit (1989) recommends that "every consultant should be allowed to devote one session a week to audit". This is substantially more than the one session a month which has been recommended elsewhere (Health Service Journal, 1988).

If we assume that a consultant is paid between $£ 30,000-£ 40,000$ then one session a week would represent a cost of $£ 3,000-£ 4,000$ per year depending on the consultant's contract. It would represent a loss of 
clinical time available for fulfilling health service contracts and income generation. It may also have an impact on the quality of care received by service consumers.

As such, the time devoted to audit should also be subject to cost benefit analysis. In other words audit must itself be audited. I should be very interested to hear from the Working Group how this might be done.

\section{St Lawrence's Hospital \\ Caterham, Surrey CR3 5 YA}

Simon Halstead

\section{References}

Health Service Journal (1988) All clear for clinical audit project, 98, 692.

The Royal College of Psychiatrists (1989) Preliminary report on medical audit. Psychiatric Bulletin, 13, 577580.

\section{DeAR SIRS}

Dr Halstead has rightly drawn attention to an important point. In the College's response to the White Paper Working for Patients with a reference to the Bulletin, we have recommended one session per week but did point out the resource implications of this.

However, it is important to emphasise that the mere collection of data is not audit. Audit must be a continuous cycle of setting standards, evaluating practice and then putting the recommendations into action. Its sole purpose is to improve the quality of care. A recent leader in the British Medical Journal of 13 January 1990, refers to this process as "the closing of the feedback loop", without which "audit may be little more than a pious exercise in self congratulation".

I am grateful to Dr Halstead for drawing attention to the problem of time. Particular difficulties may arise when doctors hoping to get together for a lunchtime meeting, are in an institution which is divided into several sites, separated by horrendous traffic jams and inadequate public transport.

There is no single solution but we hope to publish some examples of good practice in psychiatric audit after the next series of meetings of the working group.

Dr ANn Gath Registrar

\section{Clinical audit in mental handicap}

DEAR SIRS

The clinical audit for the psychiatry of mental handicap is difficult to measure as, in this particular branch, the multidisciplinary approach is crucial and the overlap of socio-economic and cultural factors, combined with the verbal communication problems of the patients, requires time to identify the diagnostic problems and to assess, treat, manage and support the patient and his family in or out of the hospital environment, in community facilities etc.

Over the past ten years we have developed the following procedure for mentally handicapped patients referred to the consultant psychiatrist in mental handicap for assessment and treatment and we are using this procedure in order to standardise the criteria for clinical audit in mental handicap.

We are interested in the views of colleagues about this issue and their methods of measuring clinical audit in mental handicap.

\section{Clinical Audit Procedure}

\section{(1) Prior to admission}

(a) Written referral from GP.

(b) Visit by community nurse for information on circumstances and background.

(c) Visit by social worker for information on social background.

(d) Out-patient appointment and/or admission to unit if acute psychosis or behavioural problems presented.

(2) On admission

(a) Examination by GP (local GPs cover admission), physical examination and relevant investigations, e.g. FBC, LFT

(b) Examination by psychiatrist or registrar for assessment, observation, any special investigation, e.g. EEG, thyroid function, blood, glucose, serum anticonvulsant levels monitoring, scanning, specialist referral eg; neurologist.

GPs carry out physical examination and make referrals for medical or surgical opinions

(c) Review and follow-up by consultant psychiatrist/registrar once or twice a week as necessary.

(d) Nursing staff and multidisciplinary team observation and assessment. Individual patient plans (IPPs).

(e) Clinical psychologist assessment, tests and advice, help in behavioural modification programmes.

(f) Physiotherapist, occupational therapist, speech therapist, social worker, nursing staff, care assistants, community nurses, relatives whenever possible, and other relevant staff.

\section{(3) On discharge}

Clinical meeting and review of progress with community nurse, social worker involvement in regular follow-up: day-care, ATC etc.

(4) Discharge letter to GP; copy to community nurse. 